\title{
The experience of married adolescent girls in northern Nigeria
}

\author{
Annabel Erulkar \\ Population Council \\ Mairo Bello
}

Follow this and additional works at: https://knowledgecommons.popcouncil.org/departments_sbsr-pgy

Part of the Demography, Population, and Ecology Commons, Family, Life Course, and Society Commons, Gender and Sexuality Commons, International Public Health Commons, Maternal and Child Health Commons, and the Medicine and Health Commons How does access to this work benefit you? Let us know!

\section{Recommended Citation}

Erulkar, Annabel and Mairo Bello. 2007. "The experience of married adolescent girls in northern Nigeria." Abuja: Population Council. 


\section{THE EXPERIENCE OF \\ MARRIED ADOLESCENT GIRLS IN NORTHERN NIGERIA}

Annabel S. Erulkar

Mairo Bello

(P Population Council

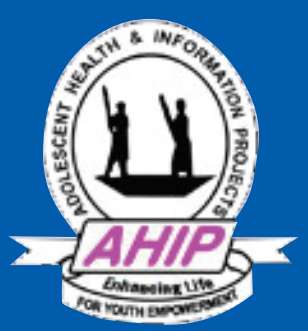




\section{The Experience of Married Adolescent Girls IN NortherN Nigeria}

Annabel S. Erulkar

Mairo Bello 


\section{(1) Population Council}

The Population Council is an international, nonprofit, nongovernmental organization that seeks to improve the well-being and reproductive health of current and future generations around the world and to help achieve a humane, equitable, and sustainable balance between people and resources. The Council conducts research worldwide to improve policies, programs, and products in three areas: HIV and AIDS; poverty, gender, and youth, and reproductive health. Established in 1952, the Council is governed by an international board of trustees. Its New York headquarters supports a global network of regional and country offices.

\author{
Population Council \\ Adamawa Plaza (3rd Floor) \\ Plot 1099, First Avenue \\ Central Business District \\ Abuja, Nigeria \\ Tel: (234) 9-870-6057; 806-778-6650
}

\author{
Population Council \\ One Dag Hammarskjold Plaza \\ New York, NY 10017 USA \\ Tel: +1 212-339-0500 \\ Fax: +1 212-755-6052 \\ www.popcouncil.org
}

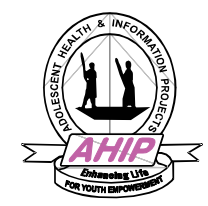

AHIP, a youth focussed Non-Governmental Organization was established in 1989 and commenced program implementation in 1992. The major focus areas are sexuality and reproductive health, social and economic issues as they relate to young people and women in Northern Nigeria. AHIP has three state branches in Kano, Bauchi and Jigawa with partners and staff in 12 Northern states. AHIP has mentored 70 NGOs in 12 Northern states to implement youth sexuality or safe motherhood programs. AHIP has over 2,000 RH leaders across 12 states and over 5000 peer health educators. The organisation produces over 100,000 IEC materials annually.

Annabel S. Erulkar, MSc, PhD is Senior Associate and Country Director with the Population Council's Office in Addis Ababa, Ethiopia

Ms. Mairo Bello is Founding Director of Adolescent Health and Information Projects (AHIP), Kano, Nigeria

\section{Photo credits}

Photos courtesy of Photoshare.

Cover: (C) Liz Gilbert/David and Lucile Packard Foundation 


\section{ACKNOWLEDgEMENTS}

This study would not have been possible without the support and guidance of a great many institutions and individuals. We gratefully acknowledge the support of MacArthur Foundation for making this study possible. Our team of in-depth interviewers worked tirelessly, even in difficult interview conditions. Ayo Ajayi, Nicole Haberland and Erica Chong gave us very helpful comments on earlier versions of this report. Finally, we thank the young people themselves who were so giving of their time, ideas and experiences and from whom we have learned a great deal about what it means to be a married adolescent girl in Northern Nigeria. 


\section{TABLE of Contents}

Executive Summary ........................................................................................................

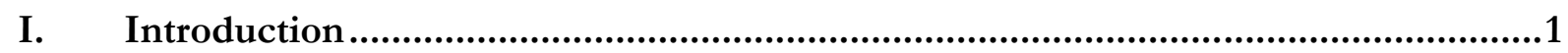

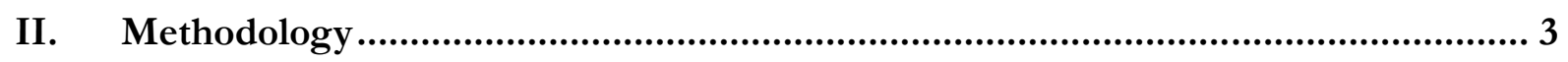

A. Secondary analysis of Demographic and Health Survey ................................................. 3

B. In-depth interviews with girls and young women from Northwest Nigeria........................................................................................................

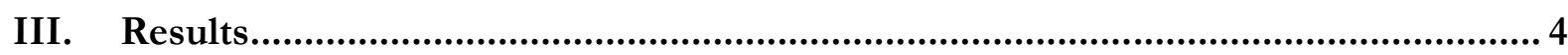

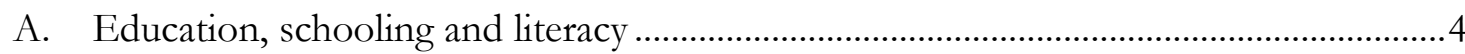

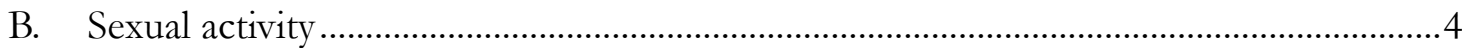

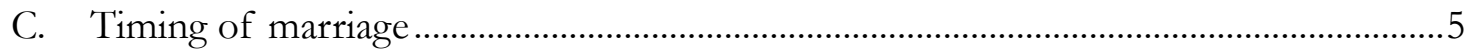

D. Decision-making regarding marriage ………..................................................................

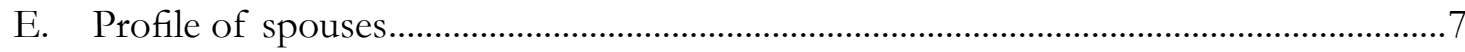

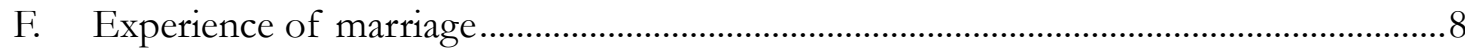

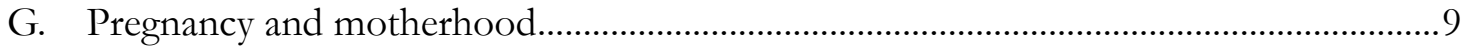

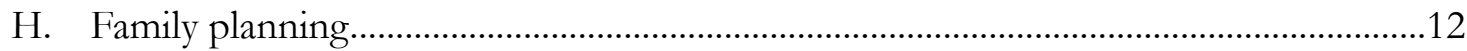

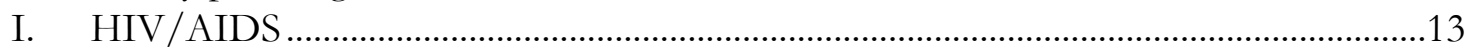

J. Access to media, health information \& healthcare .....................................................13

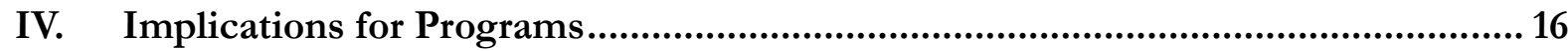

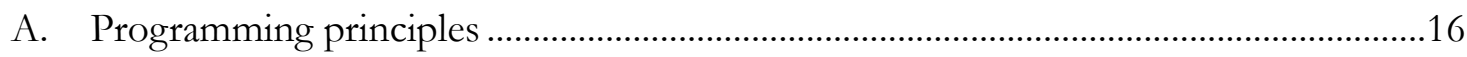

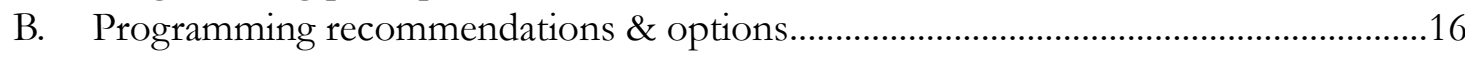

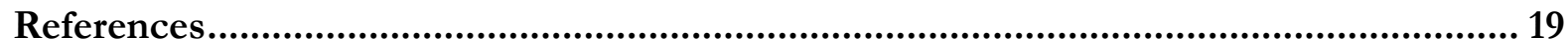




\section{EXecutive Summary}

Programs for young people in sub-Saharan Africa have been directed largely toward unmarried adolescents, neglecting the fact that a large proportion of adolescents - especially girls - are married in some settings. Early marriage is a common feature of girls' adolescence in Northern Nigeria, yet few programs are in place to support this sizeable and vulnerable group. In order to suggest directions for future programming, Adolescent Health and Information Projects (AHIP) and the Population Council examined the lives of married and unmarried girls in two geo-political regions of Nigeria, North West and North East. The study consisted of secondary analysis of the 2003 Demographic and Health Survey for Nigeria and longitudinal in-depth interviews with girls and young women with a variety of profiles.

Levels of education, rates of marriage, and sexual activity all vary by region. In the southern regions of Nigeria, girls tend to be educated and marry quite late, with median age at marriage being over age 24 in two of the southern regions. The median age at first sex for girls in southern regions is in the late teens. In contrast, Northern girls have low levels of education, marry very early, and, consequently, experience sexual initiation at earlier ages. Fifty-four percent of North West girls aged 15-24 were married by age 15, and 81 percent were married by age 18 . Early marriage is particularly prevalent in rural areas; two thirds of rural North West girls married by age 15. The majority of girls in the North experience first sex in the context of marriage, with only 5 percent of girls in North West and 11 percent of girls in North East reporting sex before marriage.

Families arrange the majority of early marriages, with some girls resisting the arrangement and others acquiescing, often considering it the will of Allah. Girls' spouses are much older than them, with an average age difference of 12 years between husband and wife. In polygamous unions (about one third of adolescent marriages), this age difference increases to an average of 18 years. These age differences may contribute to married girls' low levels of decision-making power within the household. Men made most of the decisions in the household, not only on major issues such as large purchases, but also on more mundane matters such as purchases for daily needs and meals.

Married girls in the study lacked knowledge on reproductive health, including HIV/AIDS and pregnancy. Compared to unmarried girls, they had diminished access to media sources, and to information on RH and experienced a greater number of barriers in seeking healthcare. The experience of pregnancy and childbirth was traumatic for many married girls, and many lacked information and support during this time. The study underscored the need for programs that specifically target married adolescents. New mechanisms need to be developed, as traditional youth program models such as youth centers and peer education have had limited success in reaching isolated, vulnerable girls, most of whom live in rural settings. In rural settings, home visits are probably the only feasible way to reach the most isolated girls. In urban or semi-urban settings, married girls groups can be formed as a way to combat social isolation and create a venue to reach married girls. In either case, program staff need to involve gatekeepers including husbands in their efforts to reach married girls.

Girls who marry early often get pregnant soon after. Among girls in this study, the experience of pregnancy and childbirth was confusing and traumatic, an experience for which they were not prepared. The relative acceptability of maternal health care makes this a non-threatening entry point for reaching married girls, as opposed to making information on HIV/AIDS the prominent 
topic. Using maternal health as an entry point, other subjects can be introduced, such as HIV/AIDS and family planning, and eventually gender issues and violence. AHIP is well placed to provide information on HIV/AIDS and family planning, but may need to train staff further on maternal health and safe motherhood.

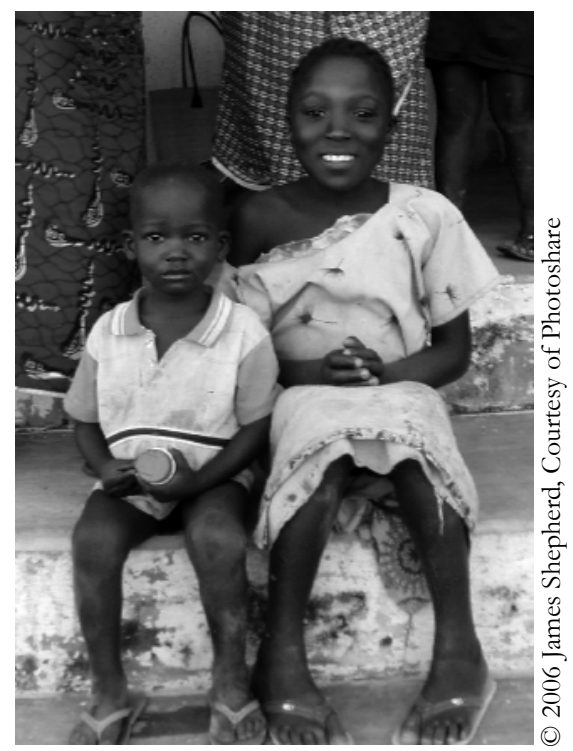




\section{INTRODUCTION}

In recent years, there has been increased public health attention to adolescents in developing countries, especially in response to their numbers, their reproductive health problems, and, most recently, to the increasing rates of HIV infection among this group (McCauley and Salter, 1995). However, the increased attention to adolescent research and programs has been focused, almost exclusively, on the unmarried, with little or no attention paid to young people who are married during their adolescent years (Mensch et al, 1998). This lack of attention is due, in part, to the changed social status that marriage confers, regardless of age. Married girls are presumed to have the same service needs and access as adult women; yet evidence is emerging that this may not be the case (Diop, 2002). Married adolescents are largely invisible, overlooked by both research and programs. At the same time, the transition to marriage is a time when girls are likely to be extremely vulnerable and in need of considerable support. Rates of HIV infection among adolescent girls in sub-Saharan Africa, especially those who are married, underscores this vulnerability (Clark, 2004).

Early marriage is largely a phenomenon of girls, not boys (Mensch et al, 1998; Singh et al, 2000). Marriage is a critical and pivotal experience in the adolescence of the majority of girls in sub-Saharan Africa, most of whom marry before age 20 (Bledsoe and Cohen, 1993). In a review of DHS data, median age at first marriage for girls is 19 or below in all countries in sub-Saharan Africa except Botswana, Burundi, and Namibia (Singh and Samara, 1996). While adolescent programmers tend to focus on premarital sexual activity, most of girls' sexual activity occurs within marriage, as do births to adolescent girls (FOCUS, 1999, Singh, et al, 2000). In Nigeria, 76 percent of sexually active girls aged 15 to 19 are married (Population Council, 2002), and 80.8 percent of first births to adolescents occur within marriage (Population Council, 2004).

Married adolescents come from poorer families and have lower levels of education compared to girls who marry after adolescence (AGI, 1998, Bledsoe and Cohen, 1993). In addition, the younger the bride, the larger the age difference between her and her spouse (Mensch, et al, 1998). While large spousal age differences are common in sub-Saharan Africa, at the extreme, it is thought that they may result in girls having diminished power in decision-making and are often reflective of the low status of women (AGI, 1998, Bledsoe and Cohen, 1993).

Most of the research on married adolescents has focused on the timing of marriage and childbearing. However, marriage has a significant impact on the quality of a girl's life, shifting her focus increasingly to family life and motherhood, rather than exploration of the work world or continuation of education (Mensch, et al, 1998, Singh and Samara, 1996). Marriage confers upon girls a new and different set of expectations, pressures and risks. Yet little research has been done to understand the new worlds of married girls, including the context of married life, how they feel about it, and how it effects their interactions with the outside world. One of the few studies in Africa examining the experience of married adolescents was a qualitative study conducted in Senegal (Diop and N'Dione, 2002, Population Council, 2002). Girls in this study cited loss of freedom and limited contact with friends and family as among the biggest changes since becoming married. Many complained that they were uninformed about their own bodies, sexuality, and reproductive health before marriage, and were unprepared for motherhood. These girls reported embarrassment and lack of resources as barriers to reproductive health services. Likewise, in a study in India, married adolescents described confusion and embarrassment surrounding the experience of menstrual disorders and symptoms of reproductive tract infections (Barua and Kurz, 2001). 
There is emerging evidence in sub-Saharan Africa that early marriage may be associated with risk of HIV infection (Glynn et al 2001, Bruce and Clark 2003, Clark 2004). In a recent study in East Africa, rates of HIV infection were at least 50 percent higher among married girls in Kenya and Zambia compared to their unmarried sexually active counterparts. Married girls typically have sex more frequently than unmarried girls, and that sex is more likely to be unprotected-largely due to pressure to get pregnant, condom use is virtually non-existent within marriage. In addition, a recent study demonstrated that husbands of married adolescent girls are older than boyfriends of unmarried girls, and thus are more likely to be HIV positive (Clark 2004).

There has been considerable public health attention paid to northern Nigeria, largely because of its high rates of maternal mortality and other pregnancy related problems. Several studies have highlighted that this region has among the highest rates of maternal death in the world as well as high rates of obstetric fistula and other complications (Adamu et al, 2003, Wall, 1998, Akpan, 2003). Many of these studies emphasize early marriage (and related early childbearing) as a risk factor, but few studies have focused on the experience of marriage in this region and what it means for a girl to be married.

This study is a collaboration between the Population Council and Adolescent Health and Information Projects (AHIP) in Kano, Nigeria. Since 1989, AHIP has been active in undertaking programs for adolescents in Northern Nigeria. Their activities include training youth advocates, organizing youth clubs, conducting adolescent reproductive health sensitization, coordinating vocational training and running multipurpose youth centers. Most of AHIP's initiatives are, whether implicitly or explicitly, directed at unmarried adolescents. Recognizing that a large number of girls are married in Northern Nigeria as adolescents and that few programs are reaching them, AHIP has a strong interest in developing programs for this subset of youth. This study is meant to serve as a basis for developing programs for married adolescents in Northern Nigeria.

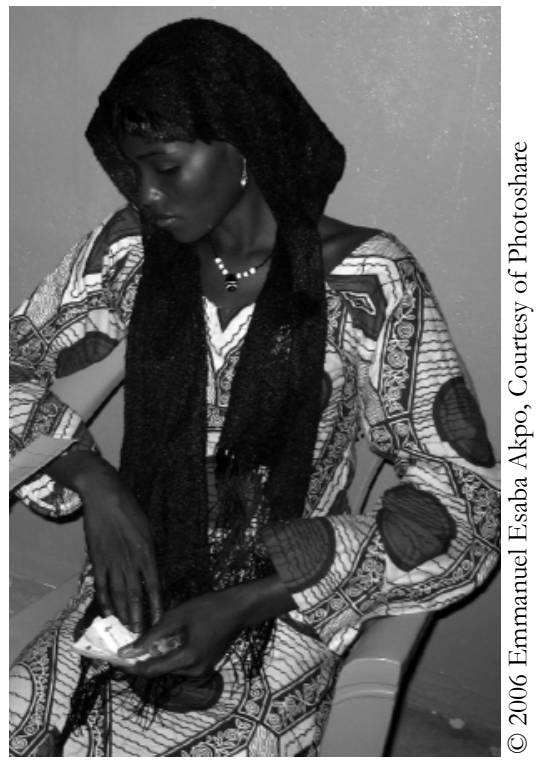




\section{Methodology}

This study utilized both qualitative and quantitative data to examine the extent and experience of married adolescents in Nigeria.

\section{A. Secondary analysis of Demographic and Health Survey Data}

Secondary analysis was conducted on the recent Nigeria Demographic and Health Survey (NPC 2004). The survey was undertaken in 2003 and had a sample size of 7,620 women aged 15 to 49. Because of our interest in adolescents and youth, analysis focused on young women aged 15 to 24. In order to understand regional differences in basic demographic indicators such as education, sexual activity, marriage, and childbirth, analyses were disaggregated by region for these variables. Additional analysis on marriage focused on respondents from North West and North East regions, the areas where AHIP operates.

When examining events such as sexual activity or marriage among those aged 15 to 24 , there are likely to be a large number of censored cases or, in other words, respondents for whom the event has not yet happened. In order to correct for this, survival analysis was conducted on variables for which there was likely to be censoring, and median estimates, rather than means, were calculated using life tables. These methods provide more accurate estimates of time-sensitive events as the current cohort of adolescents is included in the analysis, while not biasing estimates in favor of only those for whom the event has happened.

\section{B. In-depth interviews with girls and young women in Northwest Nigeria}

In-depth qualitative interviews were conducted among young women in Northwest Nigeria. Four female interviewers were selected from AHIP's program staff who had experience in qualitative interviews. An interview guide was developed which included questions on a broad range of issues including family, schooling, marriage, work and livelihoods, gender based violence, pregnancy, and childbirth. Girls were interviewed over two to three visits, both because of the broad range of topics covered and because it was anticipated that girls would open up and become more candid with each successive visit from the interviewer. ${ }^{1}$ Informed consent was obtained from all respondents. Interviews were tape recorded, translated and transcribed.

Respondents in the qualitative study represented a range of experiences including girls who were not yet married, those who were married early, those who married later and those who were divorced. Since the sample was not intended to be representative, the girls selected for interview may have been more educated and possibly more urbanized than most girls in the region. In all, 18 girls were interviewed, of which nearly half (8) had attended secondary school.

\footnotetext{
${ }^{1}$ There were indications that respondents became more candid over successive interviews. For example, in the first interview, one respondent described her relations with her co-wife as harmonious and unproblematic, whereas during successive interviews she described inter-personal problems with her co-wife as her main challenge in life.
} 


\section{Results}

\section{A. Education, schooling, and literacy}

Educational attainment and literacy levels varied between regions and by area of residence, whether urban or rural. The lowest levels of educational attainment and highest rates of illiteracy are in the North East and North West Regions. Fully 75 percent of young women who live in rural areas of North East or North West have never been to school. Similarly, 64 percent of young women in North East and 71 percent of young women in North West are illiterate. All the southern regions have high rates of educational attainment, even in the rural areas: 78 percent of rural girls in South East and 70 percent of rural girls in South South attained secondary level education or higher. Illiteracy is low in the southern regions as well; fewer than 10 percent of girls in South East are illiterate.

Table 1: Educational attainment among girls aged 20 to 29 , by region and area of residence

\begin{tabular}{|c|c|c|c|c|c|c|c|}
\hline & \multirow{2}{*}{$\begin{array}{c}\text { Literacy } \\
\text { Percent who } \\
\text { cannot read } \\
\text { or write }\end{array}$} & \multicolumn{3}{|c|}{ Urban } & \multicolumn{3}{|c|}{ Rural } \\
\hline & & None & Primary & $\begin{array}{c}\text { Secondary } \\
\text { or Higher }\end{array}$ & None & Primary & $\begin{array}{c}\text { Secondary } \\
\text { or Higher }\end{array}$ \\
\hline North Central & 48.6 & 24.1 & 17.0 & 59.0 & 31.1 & 38.8 & 30.1 \\
\hline North East & 64.3 & 38.0 & 18.5 & 43.5 & 75.5 & 12.2 & 12.2 \\
\hline North West & 70.8 & 41.7 & 15.4 & 42.9 & 74.9 & 12.4 & 12.6 \\
\hline South East & 9.7 & 4.3 & 23.2 & 72.6 & 2.4 & 19.7 & 77.8 \\
\hline South South & 17.0 & 1.6 & 14.6 & 83.7 & 6.2 & 23.5 & 70.4 \\
\hline South West & 17.5 & 1.4 & 18.6 & 80.0 & 14.9 & 40.0 & 44.1 \\
\hline
\end{tabular}

\section{B. Sexual activity}

Among sexually active girls aged 15 to 24 in Nigeria, 69 percent are married. At the same time, there is enormous regional variation in levels of sexual activity and the proportions of early sexual activity that takes place within marriage (Table 2).

Table 2: Percent of girls aged 15 to 24 who are sexually active, who are married, and who had premarital sex, by region

\begin{tabular}{lcccc}
\hline & $\begin{array}{c}\text { Percent } \\
\text { sexually active }\end{array}$ & $\begin{array}{c}\text { Median age at } \\
\text { first sex }\end{array}$ & $\begin{array}{c}\text { Percent sexually } \\
\text { active girls who } \\
\text { are married }\end{array}$ & $\begin{array}{c}\text { Percent who had } \\
\text { premarital sex }\end{array}$ \\
\hline North Central & 61.9 & 18.2 & 65.2 & 29.8 \\
North East & 71.8 & 16.5 & 91.9 & 11.0 \\
North West & 80.1 & 15.8 & 97.2 & 5.4 \\
South East & 41.6 & 20.4 & 31.9 & 33.8 \\
South South & 64.6 & 17.8 & 31.2 & 56.3 \\
South West & 46.5 & 19.3 & 42.7 & 38.2 \\
\hline
\end{tabular}

*Among those aged 15 to 24; life tables used to adjust for censoring 
The North West and North East regions have the highest percent of sexually active girls aged 15 to 24 (80 percent and 72 percent, respectively). In both of these regions, median age at first sex is remarkably low, age 16 in both regions. However, most of this early sexual activity occurs within the context of marriage. Very few girls in North West (5 percent) and North East (11 percent) report having had premarital sex. In contrast, while girls in the southern regions report a later sexual initiation, a far greater proportion have had premarital sex and a smaller proportion of the sexually active are married. Such findings suggest that for girls in the northern regions, the timing of marriage largely drives the timing of sexual initiation.

Among the in-depth interview respondents, all described that sexual initiation was within marriage. None admitted to having premarital sex, which is not surprising given the early ages at which many of the respondents were married. Most girls were hesitant to talk about the experience of sex, considering that topic of conversation taboo. The few that did talk about their first sexual experience described the experience as painful and traumatic.

The first time I had sex with my husband, I felt serious pains and was bleeding. I had to tell my auntie and she gave me some medicine then I told her that I will never allow him to do that to me again. My auntie told me that if I stop after the first time, the wound will never heal. At that time my husband was a stubborn man and anytime he came to have sex with me, I just started crying. He would tell me that Allah is blessing and rewarding me so I should not be crying. (Married girl, age 14, married at 13, 2 co-wives, 2 pregnancies, 1 st child died, 3 years education)

\section{Timing of marriage}

As with education and sexual activity, the timing of marriage varies considerably by region and area of residence. Median age at marriage is lowest among girls in North West and North East regions, at 15.8 and 16.8 years respectively. Rural girls were more likely to marry early compared to urban girls; for example, in the North West, 29 percent of urban girls married by age 15 compared to 65 percent of their rural counterparts. The timing of marriage among girls in the southern regions is later, with the median age at marriage for girls being after age 23 in all three regions.

Table 3: Percent of young women* married by age 15 and 18, by region and area of residence

\begin{tabular}{|c|c|c|c|c|c|c|c|}
\hline & \multirow[b]{2}{*}{$\begin{array}{l}\text { Median age } \\
\text { at marriage }\end{array}$} & \multicolumn{3}{|c|}{ Married by 15} & \multicolumn{3}{|c|}{ Married by 18} \\
\hline & & Urban & Rural & All & Urban & Rural & All \\
\hline North Central & 20.6 & 11.0 & 18.0 & 15.3 & 23.4 & 43.9 & 35.7 \\
\hline North East & 16.8 & 30.5 & 48.5 & 41.0 & 58.7 & 81.1 & 72.3 \\
\hline North West & 15.8 & 29.3 & 65.1 & 54.3 & 64.7 & 88.2 & 81.3 \\
\hline South East & $24.0+$ & 1.1 & 1.7 & 1.4 & 11.3 & 7.5 & 9.1 \\
\hline South South & $24.0+$ & 3.0 & 7.3 & 5.9 & 8.9 & 23.4 & 18.9 \\
\hline South West & 23.8 & 1.3 & 4.3 & 2.5 & 11.0 & 16.9 & 13.2 \\
\hline
\end{tabular}

*Among those aged 15 to 24; life tables used to adjust for censoring 
Poverty does seem to play a role in girls' marriages. Among girls in North East and North West, 67 percent of girls classified as "poorest" on the wealth index ${ }^{2}$ were married by age 15 , compared to 46 percent of "richer" girls and 25 percent of the "richest" girls. Additionally, low levels of education were associated with high rates of early marriage. Among girls in the North West and North East, 51 percent who had never been to school were married by age 15, compared with 41 percent with some primary education, and 10 percent with some secondary education.

Among girls who participated in qualitative interviews, many described the timing of marriage as dictated by tradition or by religion. In addition, some observed that girls who attend school tend to marry later than those who do not:

Every parent would like to see the daughter married. It's normal practice among the Hausa that at the age of 15 or so, one should get married. This reduces the burden on the family and brings peace to the family. Married young women, age 22, married at 15, polygamous, completed Junior Secondary School 3 (JSS])

Interviewer. Are there some people who still marry like that [early] now?

Respondent. Yes there are people who do [marry early] especially those who bave not gone to school... there is delay [for those who go to school] because you must complete the school before. (Married young woman, age 22, married at 18, Senior Secondary School [SSS] education, 1st child died, 2nd child two years, divorced at age 20)

\section{Decision-making regarding marriage}

Most of the married girls who were interviewed had their marriages arranged for them. For the most part, girls' fathers were instrumental in making the arrangements but grandmothers and the prospective husbands were also involved. Some girls readily accepted the arrangement that was being made for them, often describing the decision as an arrangement by Allah:

Interviewer. How did you get your husband - was be selected for you?

Respondent. No he wasn't selected for me. It was Allah who gave him to me. I was with my mother... he came looking for me... It was Allah who arranged it and when my father introduced me to him, he later asked me if I liked him and I said yes and he gave me to bim...

Interviewer. Looking at you at that time, do you think it was right for you to marry?

Respondent. Yes, it was right for me. (Divorced girl, age 17, married at 13 to 18 year old boy, never been to school)

A number of girls tried to resist the arranged marriage. Girls described fathers threatening them or their mothers if they did not accede to the marriage.

There is nothing I could have done because my father said if I refused, he will throw my mother out of the house unless I agree to marry. My auntie promised me that she is going to do everything I need so she has been sending me money and even assured me that she is going to send me to Mecca to perform pilgrimage and come back. (Married girl, age 14, married at 13, 2 pregnancies, 1st child died, 3 years education, 2 co-wives)

${ }^{2}$ The "wealth index" is a variable created by the DHS using the battery of questions on household amenities and possessions. 
In other cases, mothers of girls supported the father's decision to marry and the girl acquiesced, feeling she had no support in the home. During the course of this study, one of the respondents left home in an attempt to escape a marriage that was being forced upon her.

\section{Excerpt from interviewer notes: [Respondent] left after the first interview because her father brought a cousin of his to marry and she refused. The father threatened to kill her. Nobody knows her whereabouts for now, but her mother is sick about the situation and she still believes that [respondent] is with her very close friend biding somewhere. (Interviewer notes for unmarried girl, age 20, out of school)}

Because of these experiences, some girls appealed that efforts be made to prevent forced marriage, especially through sensitization of parents and community members.

\section{E. Profile of spouses}

Girls in northern regions have considerable age differences with their spouses, with a mean age difference in the two regions of 12 years. Contrary to patterns in other regions, girls who marry at young ages do not have larger age differences with their husbands compared to those who marry later. The mean age difference between a girl and her spouse is 12.2 years for girls who married before age 15 and 12.3 years for girls who married at age 18 or older. Similarly, level of education or urban-rural residence was not associated with spousal age difference. Thirty-two percent of girls with no education have a spouse who was 11 to 20 years older than themselves compared to 35 percent of girls with secondary education.

However, girls who are in polygamous unions have larger age differences with their spouses compared to girls in monogamous unions. Whereas girls in monogamous unions are, on average, nine years younger than their spouses, girls in polygamous marriage are an average of 18 years younger.

Girls with no education or primary level education are more likely to be in polygamous unions compared to those with secondary level education. Thirty-two percent of married girls with no education and 30 percent of married girls with primary education are in polygamous unions. Only 15 percent of girls with secondary education are in polygamous arrangements. Likewise, rural girls in North East and North West are more likely to be in polygamous unions compared to urban girls, with 31 percent of rural girls in polygamous unions compared to 25 percent of urban girls.

Over half of the married couples have the same level of education (56 percent), which mainly reflects couples who have never been to school. For 37 percent of married girls, their husbands have more education then they do, while 7 percent of married girls have more education than their husbands. 


\section{F. Experience of marriage}

Once married, girls' participation in household decision-making is limited (Table 4). Girls report that their husbands alone make most of the household decisions; much smaller percentages report making decisions by themselves or jointly with their husbands. The vast majority of husbands make the decisions on the girls' healthcare ( 90 percent) as well as large household purchases ( 90 percent). Men also seem to make the decisions on relatively mundane matters including daily purchases (86 percent) and choice of meal (68 percent). Men's decision making is more pronounced in polygamous households, with significantly more men in polygamous marriages than monogamous marriages making decisions on visits to relatives and food to be cooked (analysis not shown).

\section{Table 4: Decision-making within the household among married girls aged 15 to 24 , North West and North Central $(\mathrm{n}=869)$}

\begin{tabular}{lcccc}
\hline & $\begin{array}{c}\text { Husband } \\
\text { only }\end{array}$ & $\begin{array}{c}\text { Wife } \\
\text { only }\end{array}$ & $\begin{array}{c}\text { Joint husband } \\
\text { and wife }\end{array}$ & $\begin{array}{c}\text { Other } \\
\text { person }\end{array}$ \\
\hline Has final say on respondent's healthcare & 90.3 & 3.0 & 4.1 & 2.6 \\
Has final say on large household purchases & 90.2 & 2.0 & 4.1 & 3.7 \\
Has final say on purchase of daily needs & 86.3 & 2.9 & 6.6 & 4.2 \\
Has final say on visits to relatives & 70.2 & 15.9 & 11.6 & 2.3 \\
Has final say on food to be cooked & 67.8 & 20.6 & 6.0 & 5.6 \\
\hline
\end{tabular}

When girls interviewed in the qualitative study talked about the changes they experienced when they got married, the biggest change was loss of freedom and decision-making.

Interviewer: What is the difference between when you were unmarried and with your parents, and now that you are married.

Respondent: There is a vast difference... at your husband's house, there is nobody apart from your husband. With your husband, you have to ask permission before you do anything at all. (Married young woman, age 22, married at 15, polygamous, JSS3)

One of the main challenges described by girls were relationships with co-wives and mothers-inlaw.

... They [co-wives] give me very little food and warn me not to tell our husband. Whatever I want, I have to ask for it from home [parents house] and even right now I am sick, with headaches and if I ask. for money or medicine they will say they don't have any. (Married girl, age 14, married at 13, 2 pregnancies, 1 st child died, 3 years education, 2 co-wives)

... It is hell to live with a co-wife who does not respect you and who always causes confusion in the family. She was not someone I knew before she got married to my husband and my husband did not consult me before he married her. Since then, she has brought a lot of confusion between me and my husband's parents... My prayer is just that Allah should let us all live happily with each other... Marriage is something which needs a lot of commitment and patience to be able to survive it. (Married young woman, age 22, married at 15, polygamous, JSS3, pregnant with 4th child) 
Some of the girls suggested that parents should be prevented from marrying girls to husbands who already have other wives, or, at the very least consult with girls before doing so. At the same time, some respondents viewed a woman's responsibility in marriage to be patient and obedient, often citing rewards from Allah for such behavior.

It is very important to always obey your husband's instructions. This will go a long way to help them benefit from the marriage. Married women can only go to heaven on the heels of the husband. A married woman should not complain - only at the point of death - and even then you should exercise patience. It is also not good for a married woman to reveal the secrets between her and her husband. This does not help because the busband will always think that what he discussed with you is a secret not knowing that everybody outside has heard it. So I just want to appeal to all that no matter what your husband askes you to do, please do it and you will be rewarded by Allah. (Married young woman, age 22 , married at 15 , polygamous, JSS3, pregnant with 4th child)

As marriage rates are high for girls in North East and North West, so are rates of divorce. Among girls aged 15 to 24, 11 percent in North East and 8 in North West have already been divorced.

\section{G. Pregnancy and motherhood}

The median age at first birth varies from region to region, with age at first birth in the southern regions being much later (roughly age 24) than births to girls in the North (around age 18). A considerable proportion of girls in North East and North West gave birth at very young ages, by age 15. Nineteen percent of North Eastern girls and 16 percent of North Western girls had given birth by age 15 . The majority of girls in the northern regions give birth within marriage; only 4 percent of births in North East and 3 percent of births in North West were premarital. Conversely, a large proportion of first births in other regions occurred before marriage, such as 43 percent of first births in South South region.

Table 5: Median age 1st birth, births by age 15 and 18, and percent who had premarital birth, by region

\begin{tabular}{lcccc}
\hline & $\begin{array}{c}\text { Median age } \\
\text { at first birth }\end{array}$ & $\begin{array}{c}\text { Gave birth } \\
\text { by age 15 }\end{array}$ & $\begin{array}{c}\text { Gave birth } \\
\text { by age 18 }\end{array}$ & $\begin{array}{c}\text { Percent who had } \\
\text { premarital birth }\end{array}$ \\
\hline North Central & 21.6 & 7.6 & 27.4 & 17.3 \\
North East & 18.6 & 18.9 & 55.1 & 3.9 \\
North West & 18.3 & 15.5 & 59.1 & 3.0 \\
South East & $24.0+$ & 1.1 & 6.9 & 19.3 \\
South South & 23.5 & 6.0 & 19.2 & 43.4 \\
South West & $24.0+$ & 1.3 & 8.1 & 16.1 \\
\hline
\end{tabular}

The majority of ever married young women from the northern regions have children, with 34 percent having one child, 20 percent having 2 children, and 19 percent having 3 or more children.

A lot of attention has been given to the high rates of maternal mortality and morbidity in northern Nigeria. Indeed, girls in the North received very little medical care for their pregnancies and deliveries. 
Table 6: Percent of girls aged 15 to 24 who received no prenatal care, delivered at home, and received no assistance during delivery, by region

\begin{tabular}{lcccc}
\hline & $\begin{array}{c}\text { Received no } \\
\text { prenatal care }\end{array}$ & $\begin{array}{c}\text { Delivered at } \\
\text { home }\end{array}$ & $\begin{array}{c}\text { No one assisted } \\
\text { delivery }\end{array}$ & $\begin{array}{c}\text { Assisted by friendl } \\
\text { relative (non medical) }\end{array}$ \\
\hline North Central & 26.0 & 43.7 & 10.3 & 32.8 \\
North East & 48.7 & 78.9 & 11.7 & 52.2 \\
North West & 55.5 & 86.4 & 21.7 & 42.4 \\
South East & 1.8 & 14.0 & 0.0 & 7.1 \\
South South & 30.1 & 28.2 & 1.9 & 34.0 \\
South West & 3.6 & 12.0 & 0.0 & 13.3 \\
\hline
\end{tabular}

Girls in North East and North West regions have very little medical support for their first pregnancies. Roughly half of the pregnant girls in the North (49 percent in North East and 56 percent in North West) receive no prenatal care. The vast majority of these girls deliver at home (79 percent in North East and 86 percent in North West), and most have only friends or relatives assisting the delivery (52 percent in North East and 42 percent in North West). More than one out of five girls in North West (22 percent) deliver their first baby alone in sharp contrast to their counterparts in the South West where almost none delivered alone.

Many girls interviewed described the fear and confusion they experienced during their first pregnancy. Many respondents were not prepared for the experience and did not understand what was happening to them.

I had hardly started menstruating. It was my first time I saw blood come from my vagina for three days. I was afraid to tell my people but I finally told my grandmother. Then she said that I'm now a mature woman, but that's all she said. Then I started having stomach pains. My husband saw me weeping several times and he asked me why. I told him I did not know but I'm having stomach pains, not knowing it was pregnancy. (Married girl, age 14, married at 13, 2 pregnancies, 1 st child died, 3 years education, 2 co-wives)

I didn't have anybody to talk to me about how to give birth until I had the experience... All I knew is that when a pregnant woman is about to give birth they bring her back to her parents or mother, otherwise the mother doesn't tell her anything. (Married young woman, age 22, married at 16, never been to school)

Girls narrated an experience of childbirth that was often extremely traumatic. Some respondents delivered at home while some were sent to the hospital because of complications. Many of the respondents had babies who died shortly after childbirth. Indeed, DHS data shows that among girls 15 to 24 in North West and North East, 9 percent had firstborn children who subsequently died. 
Respondent: I suffered during giving birth. When I was pregnant, I did not suffer, but when I was giving birth I was sent to the hospital without me knowing because they said I had blood pressure.. I suffered and I gave birth in a dark room.

Interviewer: What is the dark room and why do they say dark room?

Respondent: I swear I do not know. Those who can't give birth are sent there and also mad women who are pregnant are sent there. Because in that room, only Allah can deliver the baby - know one knows if the person will survive or not. (Divorced young woman, age 21, married at age 15 to 18 year old boy, divorced, child at age 15, JSS3)

I delivered in the house in my Aunties room... I was there for about three days. I was feeling serious pains then was bleeding but initially it was water or urine which was coming out. They realized that my baby was sick because be never cried... he doesn't suck breast milk... they decided to give him some herbs and it made the baby's stomach become bloated. So it was decided that he must be sent to the hospital. My husband's other wives sent him and he was given drops of water... when I later went to the hospital, I was told I am also sick by the doctor and they admitted me... And the baby died - they told me he died... (Married girl, age 14, married at 13, 2 pregnancies, 1st child died, 3 years education, 2 co-wives)

Almost all the girls interviewed knew of cases of fistula among their peers. Some believed that medical professionals caused the problem.

There is only one woman I knew who had a problem [fistula]. However, it was doctors who gave her that problem. After she gave birth, she couldn't control her urine and this was caused by the midwives. (Married young woman, age 22, married at 16, never been to school)

One respondent associated the problem of fistula with early marriage:

What I think can be the possible cause of that problem [fistula] is marrying off a child or marrying at an early age. (Divorced young woman, age 22, married at 18, SSS education, 1 st child died, 2 nd child two years, divorced at age 20).

Many girls described that it is difficult for husbands to stay with girls who had fistula and that most husbands left girls with this problem.

Several of the girls who had given birth described very negative experiences including confusion about her own body and the pregnancy and trauma during the childbirth. A large number of respondents had lost their first child, which compounded the trauma of first pregnancy and childbirth. Many respondents felt that the government and other organizations should be more supportive of girls during their pregnancies:

For instance, if a woman gives birth at home, she will be given a stool to bold and when she is not able to deliver, they cannot see that. Others will not know how to use a blade or scissors to cut the vagina to enable her to give birth. Some do not know how to stitch the vagina when they cut it. But if it is a hospital, they know how to stitch, how to treat you and give you drugs that will heal the wound.... Pregnant women should be given attention and when they tell people the problems it should be given a lot of attention because its only a pregnant woman who knows what she goes through. (Married young woman age 25, married at 18 to a 30 year old, finished secondary education, teacher, 1 co-wife) 


\section{H. Family planning}

There is only limited knowledge of family planning (FP) methods among married ${ }^{3}$ women in North West and North East, with only 63 percent knowing a modern method and roughly one third (34 percent) not knowing any method at all. Moreover, approval of family planning and discussion between partners is exceedingly low. Only one quarter of young women who are married approve of family planning while only 13 percent of their husbands approve. Eighty-five percent have never discussed family planning with their husbands. Not surprisingly, the vast majority of married girls (92 percent) have never used family planning, with the main reasons for not using a method being desire for more children (47 percent), the girl's disapproval of FP (14 percent), lack of knowledge about FP (11 percent), and religious prohibition (11 percent).

Table 7: Knowledge, attitudes and practice of family planning among married girls aged 15 to 24 in North West and North East (n=913)

\begin{tabular}{lc}
\hline Knowledge of family planning & Percentage \\
\hline Knows a modern method & 63.2 \\
Knows a folkloric/traditional method only & 2.6 \\
Knows no method & 34.1 \\
Approval of family planning & \\
$\quad$ Respondent approves of family planning & 26.0 \\
$\quad$ Husband approves of family planning & 12.7 \\
Discussion of family planning with spouse & \\
$\quad$ Never discussed & 85.2 \\
Discussed once or twice & 11.7 \\
$\quad$ Discussed more than once & 3.1 \\
Use of family planning & \\
$\quad$ Never used & 92.3 \\
Used folkloric/traditional methods & 2.9 \\
Used modern method & 4.8 \\
\hline
\end{tabular}

${ }^{3}$ Analysis of family planning was restricted to married women as there are very few sexually active women who were not married in North East and North West regions. 


\section{HIV/AIDS}

There is high awareness of HIV/AIDS among young women in North West and North East, with 82 percent having heard of HIV/AIDS (Table 8). When asked to name modes of HIV transmission, significantly more married girls did not know how AIDS was transmitted compared to unmarried girls (19 percent vs. 9 percent). Among girls who could name a mode of transmission, the most commonly mentioned mode was razor blades or sharp objects, followed by sex with prostitutes.

Most girls considered themselves at no risk or small risk of getting HIV/AIDS. More married girls (71 percent) than unmarried girls (66 percent) considered their risk non-existent or small which is ironic given than very few of the unmarried girls had ever had sex. When girls who considered themselves at small or no risk were asked their reasons, most unmarried girls mentioned that they are abstinent. Among married girls, most mentioned that they avoid multiple sex partners, an answer given by 48 percent of girls in polygamous unions.

Table 8: Knowledge of AIDS and risk perception among girls 15 to 24 in North West and North East Province, by marital status

\begin{tabular}{lcc}
\hline & $\begin{array}{c}\text { Never married } \\
(\mathbf{n}=344)\end{array}$ & $\begin{array}{c}\text { Married } \\
(\mathbf{n}=906)\end{array}$ \\
\hline Heard of sexually transmitted infections & 82.8 & 85.1 \\
Heard of HIVIAIDS & 79.4 & 82.4 \\
Knowledge about transmission* (percentage mentioning & mode of transmission) & \\
Does not know how a person gets AIDS & 9.3 & 18.7 \\
By not using a condom & 1.7 & 0.7 \\
Through sexual intercourse & 24.4 & 23.2 \\
By having multiple partners & 18.9 & 17.0 \\
By having sex with a prostitute & 35.8 & 33.4 \\
Through razor blade or sharp objects & 47.7 & 32.5 \\
Risk perception about AIDS & & \\
None or small & 65.9 & 71.1 \\
Moderate or great & 4.7 & 4.7 \\
Don't know & 29.3 & 24.3 \\
Know where to get test for HIV & 39.6 & 26.0 \\
\hline
\end{tabular}

*Responses do not sum to 100 percent; multiple responses allowed

\section{J. Access to media, health information, \& healthcare}

Access to media varied by place of residence and marital status. Overall, urban girls had much higher access to media than rural girls, with urban girls reporting more frequent reading of the newspaper, listening to the radio or watching television. Within both urban and rural settings, married young women generally had less access to media than their unmarried counterparts. A far greater proportion of unmarried girls regularly read the newspaper or watched television compared to married girls. The only exception was radio, where married girls in the rural area report more radio listening compared to unmarried girls (66 percent of married girls compared to 52 percent of unmarried girls). 
Table 9: Access to media among girls 15 to 24 in North East and North West, by residence and marital status

\begin{tabular}{lcccccc}
\hline & \multicolumn{2}{c}{ Urban $(\mathrm{n}=\mathbf{4 4 5})$} & & \multicolumn{2}{c}{ Rural $(\mathrm{n}=\mathbf{8 0 7})$} \\
\cline { 2 - 3 } \cline { 6 - 6 } \cline { 6 - 6 } & & Never married & Married & & Never married & Married \\
\hline Reads newspaper or magazine & 32.8 & 17.6 & & 23.6 & 3.2 \\
Listens to radio & 75.0 & 75.9 & & 52.0 & 66.4 \\
Watches television & 73.1 & 55.1 & & 27.8 & 10.9 \\
\hline
\end{tabular}

While unmarried girls had generally greater access to media than their married counterparts, they also had greater access to information on topics such as HIV/AIDS. Young women were asked if they had learned anything about HIV/AIDS from various sources. Radio is a very important source of information, with 62 percent of married girls and 57 percent of unmarried girls learning something about HIV/AIDS from the radio. Other than radio, unmarried girls were more likely to receive information on HIV/AIDS from newspapers, pamphlets, mosque/church, and schools. The fact that unmarried girls have greater access to information on HIV from a variety of sources, could explain their greater knowledge about HIV.

Table 10: Sources of information on HIVIAIDS, by marital status

\begin{tabular}{lcc}
\hline & $\begin{array}{c}\text { Never married } \\
(\mathbf{n}=\mathbf{3 4 4})\end{array}$ & $\begin{array}{c}\text { Married } \\
(\mathbf{n}=906)\end{array}$ \\
\hline Radio & 56.9 & 61.9 \\
Newspaper, magazine & 24.5 & 9.5 \\
Pamphlet, poster & 3.2 & 0.7 \\
Mosque, church & 6.4 & 1.4 \\
Schools, teachers & 19.8 & 0.4 \\
\hline
\end{tabular}

${ }^{*}$ Responses do not sum to 100 percent; multiple responses allowed

Young women were asked a series of questions related to seeking healthcare for themselves and potential barriers including distance, transport, money for services, and availability of same sex providers. Table 11 shows the percent of girls who perceive these issues as a "problem" should they need access medical care for themselves.

Barriers to medical care varied by place of residence. Overall, urban girls perceived far fewer "problems" in terms of accessing medical care compared to rural girls. For all the barriers mentioned, fewer urban girls perceived them as a problem in accessing medical care compared to rural girls. Fewer urban girls perceived distance to the facility, having to take transport, getting money for the service, and encountering an opposite sex provider as potential problems compared to rural girls. 
Table 11: Barriers to getting healthcare for self (percent who perceive issue to be a "problem" or barrier), by residence and marital status

\begin{tabular}{|c|c|c|c|c|}
\hline & \multicolumn{2}{|c|}{ Urban $(n=445)$} & \multicolumn{2}{|c|}{ Rural $(n=807)$} \\
\hline & Never married & Married & Never married & Married \\
\hline Distance to the facility & 21.9 & 23.6 & 46.7 & 60.1 \\
\hline Having to take transport & 21.8 & 24.9 & 48.3 & 59.3 \\
\hline Getting money for services & 30.1 & 28.3 & 62.9 & 59.1 \\
\hline Concern that there is no female provider & 19.2 & 29.1 & 31.1 & 54.9 \\
\hline Not wanting to go alone & 23.8 & 25.6 & 43.0 & 50.5 \\
\hline Know where to go & 15.0 & 14.6 & 27.8 & 38.2 \\
\hline Getting permission to go & 15.0 & 15.4 & 19.2 & 35.3 \\
\hline
\end{tabular}

Even within rural areas, married girls appear to have far more constrained access to medical care compared to unmarried girls. For every concern mentioned (except money for services) married girls were more likely than unmarried girls to consider it a problem in accessing services. Married girls are more likely to have concerns about distance to the facility, having to take transport, ensuring that a female provider is available, not wanting to go along not knowing where to go and needing permission. The fact that married rural girls may have diminished access to healthcare is of concern, particularly as these girls are more likely to become pregnant early and more likely to be in need of maternity services.

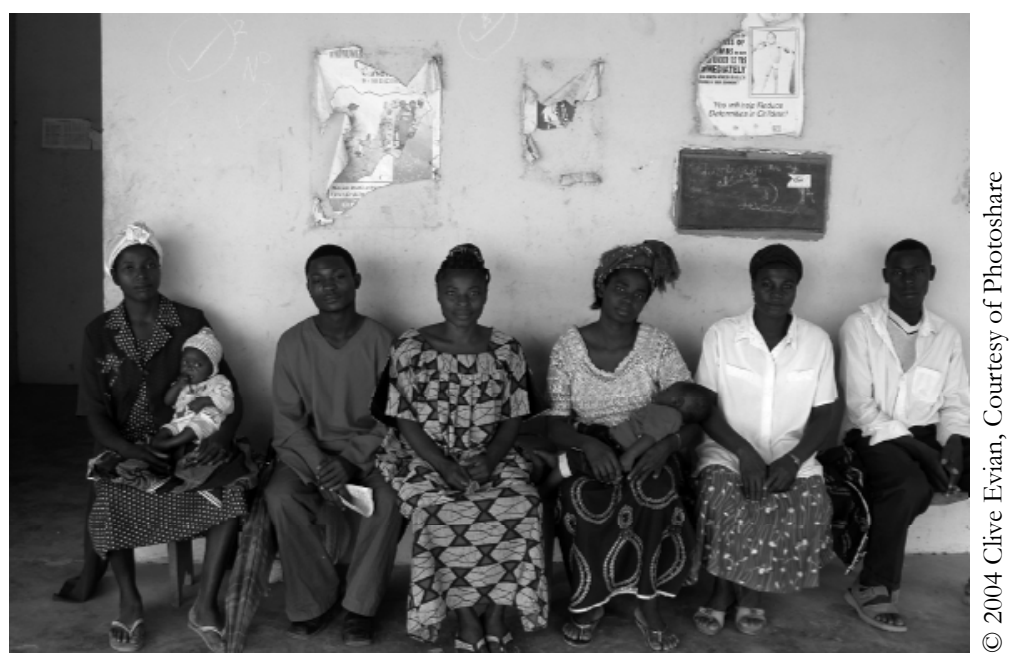




\section{Implications for Programs}

\section{A. Programming principles}

Research and programs for young people tend to homogenize the adolescent population into one genderless mass, with little regard to age or social context. Adolescent boys and girls experience rapid, intense, and gendered biological and social changes between the ages of 10 to 19. The changes and needs experienced by a 12-year-old girl are considerably different from an 18-year-old boy, not to mention the differing nature of their relationships with family, culture and society. This research highlighted how the experience of Nigerian girls differs markedly by region and marital status. Yet, few programs acknowledge differences between groups of adolescents. Greater segmentation of the adolescent population is needed in the design and content of programs, as well as greater attention to the specific circumstances of young people in local settings, especially vulnerable, hard-to-reach sub-groups of adolescents.

AHIP's and the Council's recognition of this diversity, and interest in understanding the special situation of married girls, led to this study. Findings revealed that married adolescent girls are vulnerable and in need of support, yet such girls are rarely targeted by existing programs. In addition, married girls' experiences differ. Married girls reside in both urban and rural areas, yet a greater number reside in rural region. Many married girls are lowly educated, in polygamous unions, with little decision-making power in the household. Conversely, some have achieved relatively high levels of education and are in marriages with more equitable balances of power.

Most programs implicitly assume that young people exist in a vacuum - that they have autonomy and control over what happens to them and that socio-cultural realities do not factor in. The girls interviewed for this study demonstrated that they do not make most of the important decisions in their own lives, including when and who they marry. Once married, they have even less decision making power, with most husbands making even the most mundane decisions. Programs should address the environment in which young women live and those who influence their well-being.

\section{B. Programming recommendations \& options}

Programming options related to married adolescents may fall into two distinct categories: 1) programs to delay marriage, and 2) programs to support married girls and soon-to-be or first time mothers.

\section{Delay marriage and raise the awareness of parents and community leaders about the health and rights implications of early marriage}

Over half of girls in North West are married by age 15, and over 80 percent are married by age 18. Rural girls are significantly more likely to be married early compared to urban girls. Their experience of marriage was often unwanted and traumatic, with their not knowing what was happening to them and not giving their consent to marriage. For the girls who were willing to talk about sex, sexual initiation was unwanted, traumatic, and painful, and girls were often unprepared for pregnancy. Adolescent sexual activity largely occurred within the context of marriage, with 97 percent of sexually active adolescent girls in North West married. Programs to delay girls' marriages are critical. Delaying girls' marriages in the Northern regions will, in effect, delay sexual initiation, childbirth, and the beginning of reproductive risk. 
In northern Nigeria, parents (especially fathers) are the decision makers on marriage. AHIP has a range of programs extended across a wide geographical area. The outreach programs, especially those related to advocacy, gives the organization ready access to the population, including those in power and those who make decisions on girls' marriages. One programming option is specialized training for an existing set of advocates (depending on their profile) or a new set of advocates devoted to the subject of child marriage. Educational material such as brochures could be considered, though access to such materials (especially in rural areas) may be limited because of low literacy levels. Advocates could be trained to lead community discussions on child marriage, highlighting the negative health outcomes related to early marriage and consequent early pregnancy. Discussions could take place where adults, community members and decision-makers congregate, such as religious institutions, health institutions, and/or local administration. As with all programs of this nature, a simple but effective management information system (MIS) is critical, which tracks the volume, profile and content of contacts, and allows managers to monitor program activity and coverage.

\section{Focused interventions to support married girls}

Married adolescents are a special category. They are often considered 'women' by virtue of their marriage, but are still children in terms of their age and experience. In many African settings, once a girl is married, she is not supposed to socialize with her unmarried peers, which essentially cuts her off from the social network to which she is accustomed. As a married woman, her new social set is supposed to be other married women, but most of these women will be older and not likely to be an easy social 'fit.' As such, married girls straddle two worlds and frequently find themselves alone and isolated in their new marital homes. Indeed, girls in this study described being isolated and under the control of their husbands and co-wives. Their isolation compounds their diminished access to information and services, making them not easily reached by conventional mechanisms such as youth centers or peer education. It is unlikely that young married women in Northern Nigeria would be allowed to visit youth centers, given their restricted mobility, limited autonomy, and considerable domestic duties. Those that are allowed to visit are probably not representative of the 'typical married adolescent' and are likely to come from more advantaged or educated households. Moreover, a large proportion of girls in rural areas of the Northern regions are married, where households are disbursed and difficult to reach.

\section{Mechanisms to access married adolescents}

As they are a special category, specialized programs for married girls are likely to be more effective than programs in which they are one of many different target groups. Including married adolescents as one target group, along with other groups, may result in the more accessible groups receiving most of the services and the married adolescents, largely forgotten. Given their social isolation, their burden of work that keeps them at home, and dispersion in the rural areas, one of the major challenges to programming is in reaching them in the first place. Programs may need to overcome this via tailored outreach or mobilization mechanisms, such as home visits or group formation.

In both urban and rural areas, programs might directly bring information or rudimentary services to the girls/young women in their homes or compounds and make special efforts to identify and draw in the most isolated, vulnerable married girls into the project. In home-based programs such as these, special efforts should be taken to involve and solicit the input and approval of gatekeepers, including spouses, in-laws, and perhaps co-wives. In rural areas, adapting a CBD-type approach may be feasible. 
In urban or semi-urban areas, there is probably sufficient population density to form married girls groups. Groups for married girls not only combat social isolation and increase social networks, but they create venues through which girls in this special category can be reached. As with home-based activities, special care is needed to involve gatekeepers during formation of groups.

The community based outreach or group mechanisms should also provide linkage to clinical services. Given limited mobility and the barriers that married girls perceive in accessing services, program staff should be available to facilitate access to services, including accompanying a girl to the clinic.

\section{Special support to married girls}

This study underscored the vulnerability of married girls. Married girls are less likely than their unmarried counterparts to be knowledgeable on reproductive health or HIV/AIDS, or to have access to such information. Yet, arguably, they are more in need of RH information than their unmarried counterparts. Many of these girls marry early in settings of extreme poverty, poor nutrition, and limited education. Efforts to better support girls in their transition to marriage (if marriage cannot be delayed) and motherhood (which usually follows), include information and support during pregnancy. Many girls were extremely uninformed about pregnancy and most relied on family members for support during pregnancy and delivery. Programs to support girls before and during pregnancy, and at delivery are critical in combating the confusion and trauma during pregnancy and childbirth as well as the reproductive morbidity and mortality that accompanies early first birth.

The relative acceptability of maternal health care may make this a non-threatening entry point for reaching married girls, as opposed to making information on HIV/AIDS the prominent topic. Using maternal health as an entry point, other subjects can be introduced, such as HIV/AIDS and family planning, and eventually gender issues and violence. AHIP is well placed to provide information on HIV/AIDS and family planning, but may need to train staff further on maternal health and safe motherhood. The involvement of clinical staff will also be necessary, especially in the clinics to which girls are referred. These staff need to recognize that the client (i.e. married girl) may have limited say in sexual and reproductive decision-making, and may have special needs, concerns and interests because of this.

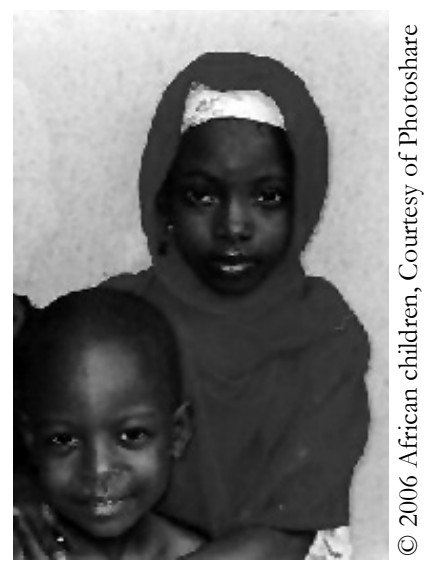




\section{REFERENCES}

Adamu YM, Salihu HM, Sathiakumar N, Alexander GR. 2003. Maternal mortaily in northern Nigeria: A population based study, European Journal of Obstetrics, Gynecology and Reproductive Biology, Aug 15;109(2):153-159.

Akpan E. 2003. Early marriage in eastern Nigeria and the health consequences of vesico-vaginal fitulae among young mothers, Gender and Development, Jul; 11(2): 70-76.

Alan Guttmacher Institute (AGI). 1998. Into a new world: young women's sexual and reproductive lives. New York: Alan Guttmacher Institute.

Barua A, K Kurz. 2001. Reproductive health seeking by married adolescents in Maharashtra, India, Reproductive Health Matters, Volume 9, No. 17, May.

Bledsoe C, B Cohen. 1993. Social Dynamics of Adolescent Fertility in sub-Saharan Africa. Washington DC: National Academy Press.

Bruce J, Clark S. 2004 "The implications of early marriage for HIV/ AIDS policy” brief based on background paper prepared for the WHO/UNFPA/Population Council Technical Consultation on Married Adolescents. New York: Population Council.

Clark S, 2004. "Early marriage and HIV risks in sub-Saharan Africa" Studies in Family Planning, 35(3) 149-160.

Diop N, JC N’Dione. 2002. Etude Exploratoire du Vecu des Adolescentes Mariees, Dakar, Senegal: The Population Council, November.

FOCUS on Young Adults/Pathfinder. 1999. Reaching Newlywed and Married Adolescents. Washington DC, FOCUS on Young Adults Project.

McCauley A, Salter, C. 1995 "Meeting the Needs of Young Adults," Population Reports, series J, no. 41.

Mensch, B, J Bruce, M Greene. 1998. The Uncharted Passage: Girls’ Adolescence in the Developing World. New York: Population Council.

National Population Commission, Nigeria, and ORC Macro. 2004. Nigeria Demographic and Health Survey 2003, Calverton Maryland: National Population Commission and ORC Macro.

Population Council. 2001 Facts about adolescents from the Demographic and Health Survey - Statistical tables for program planning: Nigeria 1999. New York.

Population Council. 2002. Married Adolescents: Senegal, Research Summary, Dakar, Senegal: The Population Council, March.

Singh S, D Wulf, R Samara, Y Cuca. 2000. Gender Differences in the Timing of First Intercourse: Data from 14 Countries. International Family Planning Perspectives, 26 (1): 21-28, March.

Singh S, R Samara. 1996. Early Marriage Among Women in Developing Countries. International Family Planning Perspectives, 22: 148-157.

Wall LL. 1998. Dead mothers and injured wives: the social context of maternal morbidity and mortality among the Hausa of Northern Nigeria, Studies in Family Planning, Dec: 29(4): 341-359. 


\section{(P Population Council}

www.popcouncil.org

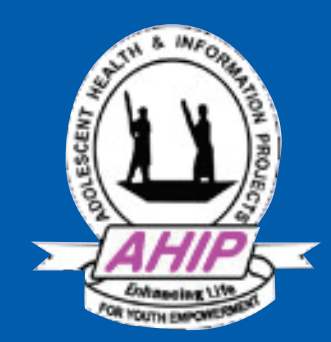

www.ahipnig.org 